\title{
The Public Sphere as Site of Emancipation and Enlightenment: A Discourse Theoretic Critique of Digital Communication
}

\author{
David Ingram \\ Loyola University Chicago, dingram@luc.edu
}

Asaf Bar-Tura

Follow this and additional works at: https://ecommons.luc.edu/philosophy_facpubs

Part of the Civic and Community Engagement Commons, Communication Technology and New Media Commons, Inequality and Stratification Commons, Interpersonal and Small Group Communication Commons, Mass Communication Commons, Philosophy Commons, Political Theory Commons, Politics and Social Change Commons, Social Influence and Political Communication Commons, Social Media Commons, and the Speech and Rhetorical Studies Commons

\section{Author Manuscript}

This is a pre-publication author manuscript of the final, published article.

\section{Recommended Citation}

"The Public Sphere as Site of Emancipation and Enlightenment: A Discourse Theoretic Critique of Digital Communication" (co-author Asaf Bar-Tura), from D. Boros and Jim Glass (eds), Re-Imagining Public Space: The Frankfurt School in the 21st Century (Palgrave Macmillan, 2014).

This Book Chapter is brought to you for free and open access by the Faculty Publications and Other Works by Department at Loyola eCommons. It has been accepted for inclusion in Philosophy: Faculty Publications and Other Works by an authorized administrator of Loyola eCommons. For more information, please contact ecommons@luc.edu. c) (†) $\Theta$

This work is licensed under a Creative Commons Attribution-Noncommercial-No Derivative Works 3.0 License. (c) 2014 Boros and Glass 
The Public Sphere as Site of Emancipation and Enlightenment: A Discourse Theoretic Critique of Digital Communication

David Ingram \& Asaf Bar-Tura

October 4, 2013 (revised)

Habermas claims that an inclusive public sphere is the only deliberative forum for generating public opinion that satisfies the epistemic and normative conditions underlying legitimate decision-making. He adds that digital technologies and other mass media need not undermine - but can extend - rational deliberation when properly instituted. This paper draws from social epistemology and technology studies to demonstrate the epistemic and normative limitations of this extension. We argue that current online communication structures fall short of satisfying the required epistemic and normative conditions. Furthermore, the extent to which Internet-based communications contribute to legitimate democratic opinion and will formation depends on the design of the technologies in question.

We develop our argument in four steps: First, (1) we situate Habermas's discourse theory of democracy as a response to the crisis of liberal democracy, which asks whether and how the public sphere can remain a site of enlightenment and emancipation in an age of mass media and communications. Second (2), we identify an epistemological deficit in Habermas's thinking about contemporary communication flows in the public sphere, namely, we show that Habermas does not properly account for the affective dimension of reasoning, thus highlighting the shortcomings of mediated communications. Third (3), we identify a normative deficit in Internet-based communications when considered through Habermas's discourse-theoretic framework. In particular, we critically examine whether digital media in fact allow for more marginalized voices to enter public discourse, thus democratizing the public sphere, and argue that there are good reasons and good empirical evidence to suggest that this is not the case. We conclude (4) by emphasizing that the design of the technologies under discussion, and hence their social consequences, are not predetermined. Technology is always underdetermined and always embodies specific values. Hence, the design of the Internet itself, and the applications we use through it, begs a public discussion based on democratic values.

\section{Discourse Theory as a Response to the Crisis of Liberal Democracy}

Ninety years ago Carl Schmitt observed that liberalism's faith in rational discussion as the via regia toward legitimating a rule of law based on consensus had finally revealed itself for what it truly was: an empty idealism premised on the hegemony of the bourgeoisie as the proclaimed representative of humanity's universal interests (Schmitt, 1985). The enfranchisement of the working class had transformed parliament into a more inclusive body whose new mandate, Schmitt observed, was to advocate for the particular interests of partisan constituencies through propaganda and backroom dealing. Schmitt further noted that this perversion of the Millian ideal of representative democracy found parallel 
expression in the unprecedented use of new techniques of mass communication in shaping public opinion by means of spectacle and propaganda.

Schmitt's diagnosis of the crisis of liberal democracy would resurface forty years later in Habermas's classical critique of the structural transformation of the public sphere (Habermas, 1989). Writing today, it would seem that political life, then as now, has barely changed. If anything, the propagandistic nature of political discourse as staged spectacle has become even more apparent. To be sure, the concentration of media ownership and the impact of big money on shaping public opinion is only one side of the story. One could cite counter-movements in mass media - such as the explosion of cable TV networks and public access broadcasting as well as the emergence of independent journalism and blog threads that promise greater diversity and inclusion of opinions. Digital social media are but the latest examples of communication technology that promise to revitalize the public sphere as a popular democratic forum for free, equal and inclusive discussion. It behooves critical theorists to examine this potential in more detail. Can virtual communication replace faceto-face dialogue as a medium for rational enlightenment and self-transformation?

Habermas introduces his discourse theory in response to precisely this question. Dissatisfied with Schmitt's democracy/liberalism antithesis, he argues that both legitimating principles (consent of the majority and respect for individual rights) have a common ground in rational deliberation. Indeed, as is well known, Habermas defines normative validity in general - be it moral, ethical, or legal - in terms of a procedure of rational discourse. Valid are precisely those norms that all affected would agree upon subsequent to an inclusive, free, and equal dialog in which conviction based on the best argument holds sway. This counterfactual ideal perfectly captures the moral point of view - that each person must be accountable to others, so that their reasonable (justifiable) dissent must be respected. When transferred to the legal sphere the discourse principle retains this reference to morality but with an important twist. The basic equal rights that it stipulates do not impose a reciprocal moral duty to justify one's actions but instead open up a range of permissible action to which the individual rights holder need be accountable to no one. Such liberal rights, however, are but empty principles of freedom unless politically qualified by another application of the discourse principle, this one involving a procedure of democratic consent.

The principle of democracy constructed on the basis of the principle of discourse thus embodies liberal features - basic individual freedoms, equal protection from discrimination, separation of powers, and the rule of law. Suffice it to say, Habermas's discourse theory has implications for the way in which the abstract features of a procedurally just liberal democracy are concretely interpreted and institutionalized. The constitutional flow of institutional power - from legislative deliberation and enactment to executive and judicial application - should be entirely responsive to public opinion undistorted by excessive influence emanating from government elites and private interests.

In a recent essay on normative democratic theory and empirical mass media studies, Habermas formulates the liberal supposition that rational discourse can legitimate democratic decision-making as an assumption

- That relevant issues and controversial answers, requisite information, and appropriate arguments for and against will be mobilized;

- That the alternatives which emerge will be subjected to examination in argumentation and will be evaluated accordingly; and 
- That rationally motivated 'yes' and 'no' positions on procedurally correct decisions will be a deciding factor (Habermas, 2009: 162)

These three suppositions are satisfied differently depending on what public arena of the "public sphere" they occur within: (1) the formal institutional debates that occur within the political system; (2) the informal, everyday communications that occur within civil society; or (3) the passive reception and reflective consideration of abstract information and public opinion that occur in mass media (159). Beginning with the "peripheral" sphere of political life that is furthest removed from political decision-making proper, Habermas identifies civil society, composed of "citizen groups, advocates, churches, and intellectuals," as well as the social movements and social networks around which they organize themselves, as responsible for communicating concerns of common interest, specifically about social injustices (163). The "political communication" generated through physical encounter and social media contains a large quantity of non-discursive expressions of social discontent, involving the use of "story-telling and images, facial and bodily expressions in general, testimonies, appeals, and the like" (154). The "wild" (spontaneous and unregulated) nature of political expression within civil society, ranging from loud demonstrations of civil disobedience to dispassionate arguments in academic forums, stands in sharp contrast to the highly regulated arguments that occur within the center of political life, the political system, which is charged with responding sensitively to the most vocal concerns circulating in civil society as well as those emanating from lobbyists representing "industry and the labor market, health care, traffic, energy, research and development, education" and other "functional subsystems" (163). Less inclusive and free, but procedurally fairer, arguments conducted by government officials within institutional settings, Habermas notes, abide by strict courtroom and parliamentary procedures that are designed to ensure that all participating parties have an equal voice in debating policies. But these rules impose rational orderliness by subjecting speakers to severe time limits, legal frameworks, and rules of civil decorum that constrain freedom to argue freely and exclude less mainstream points of view. Intermediary between civil society and the political system is the massmediated sphere of communication, which is charged with condensing, refining, weighing, and selecting public opinions emanating from civil advocacy groups, special interest lobbyists, and politicians. When properly instituted, with appropriate government regulation ensuring independent, fully representative, and roughly equal access, this arena of the public sphere can counteract shortfalls in discursive rationality that dominate in civil society and government by disseminating opinions more widely and by subjecting already filtered arguments to a second level of public reflection.

Any possibility of democratic process producing rational, viz., legitimate, decisions thus depends on the proper institution of the mass media. Assuming that rational argumentation can have an impact on cooperative learning and political problem solving an assumption confirmed by empirical studies ${ }^{1}$ - the question arises whether mass media can function as well as face-to-face focus group discussion in generating rational public opinion formation conducive to reaching consensus.

\section{The Affective Deficit of Digital Communications}


A new structural transformation of the public sphere driven above all by digital technological revolutions has accelerated and intensified the diversity of information flows. It may seem that the resulting "communicative liquefaction of politics" has made it difficult for any entity to monopolize political communication (154-5). Yet Habermas cites three factors that speak against the prospect that this upsurge in political communication tracks an increase in rational deliberation.

[T] wo deficits in particular immediately stand out: the lack of straightforward, faceto-face interactions, between really (or virtually) present participants, in a shared practice of collective decision-making; and the lack of reciprocity between the roles of speakers and addressees in an egalitarian exchange of opinions and claims. In addition, the dynamics of mass communication betrays relations of power which make a mockery of the presumption of a free play of arguments. The power of the media to select messages and to shape their presentation is as much an intrinsic feature of mass communication as the fact that other actors use their power to influence the agenda, content, and presentation of public issues is typical of the public sphere (154).

To begin with, mass communication "remains 'abstract' in so far as it disregards the actual presence of the more or less passive recipients and ignores the immediateness of the concrete glances, gestures, thoughts, and reactions of those who are present and addressed" (156). By not being "open to the game of direct question and answer, the exchange of affirmation and negation, assertion and contradiction," mass communication detaches the propositional content of opinions from the validity claim structure of everyday communicative interaction, in which opinions are linked to a process of argumentative challenge and redemption. In this respect it is more like a "price regulated network of transactions between producers and consumers" (ibid).

Secondly, mass communication possesses an "asymmetrical structure," insofar as it reduces addressees to the status of passive spectators and consumers. Journalists and politicians are like actors on a stage vying for the public's applause. It is true, of course, that the Internet has provided a censure-free mechanism for political communication in authoritarian regimes that has led to remarkable (if short-lived) democratic victories (as witnessed, for example, by the Arab Spring). But in liberal democracies the "chat rooms" that seem to have "revived the historically submerged phenomenon of an egalitarian public of reading and writing conversational partners and correspondents" have largely crystalized around partisan or otherwise parochial niche audiences, thereby belying the globalizing and decentering potential of the Internet and, Habermas adds, fragmenting the public sphere further into entrenched and closed interest groups (158).

That said, Habermas insists that these structural deviations from rational discourse do not necessarily mean that mass media fail to contribute to rational deliberation (158). They contribute by filtering inputs from elites within civil society, government, and functional subsystems in the form of published opinions, and then reflectively generating public opinions ("clusters of controversial issues and inputs to which the parties concerned intuitively attach weights in accordance with their perceptions of the cumulative 'yes' and 'no' stances of the wider public" as conveyed by a "representative spectrum of pooled opinions reflected in survey data") (165). Beyond this, mass media also enable a secondary 
reflection on (already critically reflected) public opinion, which generates considered public opinion, by which Habermas understands "a pair of contrary, more or less coherent opinions, weighted in accordance with agreement and disagreement, which refer to a relevant issue and express what appears at the time, in light of available information, to be the most plausible or reasoned interpretations of a sufficiently relevant -though generally controversial - issue" (166). Considered opinions "fix the parameters for the range of possible decisions [made by political elites] which the public of voters would accept as legitimate" (ibid). In this way, properly functioning mass media perform two invaluable tasks in democratic deliberation: they return to civil society its own messages of discontent, now reflectively worked up in the form of considered public opinion; and they place such opinion before institutional deliberative bodies, commenting and observing how well such bodies incorporate said opinion into their agendas and debates (162).

However, mass media function properly only if the power structures of the public sphere and the dynamics of mass communication permit it. The public sphere is influenced by political power, which shapes the legal regulations that constitute the diversity and independence of the mass media. It is influenced by social power (especially economic power), which must be exercised in a relatively transparent manner; and it is influenced by media power, which shapes the content and formatting of public opinion according to its own professional code of integrity (fairness and independence). Although Habermas concedes that sectoral and government elites have a financial and organization advantage in shaping public opinion according to their preferences relative to the "weak" and "dispersed" publics that form civil society, he thinks that their strategic interventions can be checked by the reflective counter-responses of a well regulated mass media. Whether this actually happens depends not only on the independence of the media but - most importantly - the "motivational dispositions and cognitive abilities" of average citizens. Citizens, Habermas contends, "need not possess a large body of knowledge about politics" in order to be knowledgeable in their reasoning about political choices" (172-3).

Habermas expresses considerable skepticism about whether these two conditions are in fact met. In addressing the problem of independence, he notes that mass media may be "incompletely differentiated" from their social and government environments. This was the case with Italian government's post war monopoly over the broadcasting system, when each of the three major political parties recruited media personnel from its own ranks. A potentially more sinister instance occurred when the National Security Agency enlisted such telecommunications and Internet giants as Verizon, Telstra, Google, and Facebook in tracking user data. Lack of independence may also take the form of a "temporary dedifferentiation," as when media and government collude for mutual advantage (favorable news coverage in exchange for access) (174-6).

A second pathology manifests itself in citizen's overly passive and uncritical consumption of public opinion. Consumption is unequally partitioned among the various sectors of society depending on educational achievement, social class, and cultural marginalization (see below). Apathy, powerlessness, and cynicism, largely in response to the devolution of political campaigns into image-making spectacles and the debasement of news to "infotainment" (the oversimplification of complex issues), also reinforces the passive consumer mentality of citizens (178-80).

Counterbalancing this gloomy diagnosis, Habermas cites studies showing that citizens' "ascriptive ties between political behavior and social and cultural backgrounds 
have increasingly loosened" (178). Such loosening suggests a growing "independence of political attitudes from determinants such as place of residence, social class, or religious affiliation" (ibid). From this Habermas infers that public reason may be gaining the upper hand over parochial prejudice when it comes to thinking about particular issues. The new media-generated interest in participating in multiple "issue publics" centered on immediate (short term), non-economic concerns has "pluralized" participation in distinct but overlapping publics, thereby weakening monolithic partisan loyalties, ideological antagonisms, and narrow group- and identity-based patterns of political association (ibid).

Habermas's optimism about the impact of mass media in emancipating people from prejudice and negative out-group stereotyping will receive further scrutiny below. Suffice it say, Habermas remains ambivalent about the potential of mass media in facilitating rational deliberation; although they are not structurally prevented from functioning this way, social reality conspires to render such an outcome unlikely. Continuing with this line of reasoning, we will consider how current forms of digital mass media exacerbate the pathological tendencies noted above. But first we want to question Habermas's bold assertion that mass media are not structurally prevented from functioning as rational media.

Habermas mentions that mediated communication lacks the critical give-and-take that occurs in face-to-face conversation. What mediated communication potentially possesses - and what face-to-face conversation lacks - is a critical distance from the immediate spoken utterance that, in Habermas's own words, enables a kind of delayed, secondary reflection on what is said by other third parties. Furthermore, face-to-face conversations can prove intimidating to people who have speech impediments or other physical characteristics that place them at a disadvantage in arguing. Disembodied communication can be less discriminatory, as Habermas (speaking of early disadvantages suffered as a result of his own speech impediment) remarks. In any case, the apparent structural disadvantage of abstract mediated communication disappears when considering interactive media and chat rooms. If anything, these forms of communication appear to combine the advantages of direct conversation and mediated reflection.

But do all structural disadvantages associated with mass media disappear? It would seem not. In discussing how citizens' political reasoning today is less overtly driven by "ascriptive" features of their social positioning such as race, gender, ethnicity, social class, and religion and more focused on the abstract merits of public policies, Habermas downplays a problem whose seriousness he elsewhere acknowledges, namely the way that social positioning indirectly biases our perception and critical analysis of policy issues. ${ }^{2}$ For instance, in the United States an affluent, white suburbanite's critical processing of information and arguments regarding government entitlements for poor people may be distorted by a negative emotional response to the poor, colored by a stereotypical understanding of who the poor are (for example, that they are undeserving racial minorities). Such unconscious, socially-positioned in-group/out-group attitudes may not be dislodged without the aid of positive, face-to-face encounters with a fairly broad swath of poor people. Witness the recent sea-change in Americans' regarding the acceptability of same sex marriage. Would this change have occurred on the basis of rational arguments alone, in abstraction from more personal engagement with gay citizens?

Perhaps mass media have contributed to public acceptance of gays (if so, their record here as elsewhere is uneven). The larger point is that cognition (reasoning) has an 
affective dimension; the reception of reasons requires empathy, which some media can provoke better than others. Empathy requires communication, which need not be dialogical or even personal (reading accounts of others experiences as narrated by journalists may suffice to produce empathetic understanding). Indeed, embodied communication may either advance or hinder empathetic understanding. However, just as the emotional transference between analyst and analysand in psychoanalysis transpires most effectively in person-to-person dialog, so too the therapeutic overcoming of defensive reactions and resistances vis-à-vis others may require really encountering them. Those outgroups who resist or threaten our particular idealizations of security and happiness are perceived as threats to our very identity, and so call forth feelings of guilt, resentment, and anxiety. We objectify them as if they were outside the bounds of empathetic identification and we demonize them by blaming them for our problems, projecting onto them our own insecurities and feelings of inferiority. So, although mass-mediated discourse can disseminate positive or negative images (and stereotypes) of marginalized groups that aid or frustrate empathy towards them, the real work of dissolving prejudice may require faceto-face efforts at mutual understanding (Druckman, 2004, 675).

\section{Are All Internet Users Created Equal?}

Above we have examined the epistemological limits and possibilities of mass media vis-àvis the achievement of rational discourse and concluded that some of the therapeutic advantages of face-to-face dialog concerning the facilitation of empathetic receptivity toward standpoints and arguments advanced by others who are socially positioned differently than ourselves might be lost at this abstract or distanced level of communication. Now we turn to the normative claim in Habermas's deliberative framework, namely, that a public sphere that allows for deliberation that includes the communication community of all those affected, especially those who are socially marginalized and disempowered, is more just, and decisions based on such deliberations are more legitimate. In particular, we critically examine whether digital media in fact allow for more marginalized voices to enter public discourse, thus democratizing the public sphere, and argue that there are good reasons and good empirical evidence to suggest that this is not the case.

In 2006 Time magazine chose a surprising figure as its "Person of the Year": You (Grossman, 2006). The subtitle on the cover read: "Yes, you. You control the information age. Welcome to your world."3 This choice reflects the prevalent notion that the Internet may lead to more intercultural understanding, more citizen participation, and a more flourishing and vibrant democracy (Kellner, 2000; Bar-Tura, 2010).4 Indeed, the development of communication networks has historically been a powerful force in shaping the political public sphere and the meaning of discourse and action within it. Today many theorists consider digital technology, and especially the rapid development of the Internet, as a democratizing medium that promotes wider access and participation in the political public sphere (Habermas, 2009, 143). Many who claim that the Internet is "democratizing" politics often mean that the Internet is driving a redistribution of opportunities for political influence. That is to say, more people can get involved in civic and political activities, can increase their participation in the political public sphere, and have more access to positions in which they can influence public debate. This change, it is often claimed, challenges the 
monopoly of traditional elites over meaningful influence of the public sphere and the political process (Hindman, 2009, 6). So, can digital communications fulfill the promise of participatory parity?

In his attempt to account for the way in which peripheral topics enter the center of public debate, Habermas argued in Between Facts and Norms that journalists, publicity agents, and members of the press "collect information, make decisions about the selection and presentation of 'programs,' and to a certain extent control the entry of topics, contributions, and authors into the mass-media-dominated public sphere" (Habermas, 1998, 376). Due to the increasing complexity, cost, and centralization of effective channels of mass communication, he pointed to increasing pressure on the media to select topics for public discussion. He saw the spontaneous associations of civil society as forming "the organizational substratum of the general public of citizens," (Habermas, 1998, 376) while the mass media and large agencies form the institutional "backbone" of the public sphere (Habermas, 2009, 131-137).

However, with the advent of online social networks, blogs, and other "bottom up" and "peer-to-peer" digital media, such centralization seems to have been diffused. It seems that citizens are no longer reliant on centralized institutions for their information, and are not dependent on the editorial selection process. "Media power," as Habermas called it, seems to have waned. The media gatekeepers no longer seem to control the flow of information. Indeed, the gates seem to have been stampeded by millions of Internet users who are raising their voices and speaking directly to their online audiences. Is this an accurate description? We now turn our attention to the political economy of the Internet, and how it creates and sustains socio-economic barriers to accessing the digital public sphere.

\section{The Access, Use and Skill Divides}

Since the use of the Internet has become widespread, there has been much focus on what has been dubbed the "digital divide." This refers to the unequal access to Internet services among various demographic groups (Lamb, 2013, 12-24). This inequality often follows socio-economic inequalities and as such calls into question the degree to which the Internet has an equalizing socio-economic effect. What follows is some sobering data regarding Internet access.

Since its introduction to public use on a mass scale, the Internet has rapidly expanded, growing from 16 million users worldwide in 1995 to over 2.2 billion in 2012 (Lamb, 2013, 3). But this growth is not spread evenly among all demographic groups. Furthermore, while one might assume that this inequality is only between populations of developed and developing countries, this is hardly the case. That is, inequalities in access to the Internet persist in the United States, and can be traced along clear socio-economic lines. Race and gender continue to be predictors of access to the Internet in the US. Disparities in access and use of Internet technology still exist between Black citizens and Whites, favoring the latter. Similar disparities exist between women and men, again favoring the latter (Lamb, 2013, 6-7). That said, there are signs that disparities in Internet access along lines of race and gender are slowly closing (Lamb, 2013, 12). 
A 2012 study found that while one in five Americans does not use the Internet, by far the social groups most negatively affected by the digital divide in the US are the elderly, the poor, and the uneducated (Lamb, 2013, 4). More precisely:

- Education: Educational attainment is one of the strongest predictors for Internet access, as $43 \%$ of adults without high school educations use the Internet, versus $71 \%$ of high school graduates - and $94 \%$ of college graduates.

- Income: Household income is strongly correlated to Internet use, "as only $62 \%$ of those living in households making less than $\$ 30,000$ per year use the internet, compared with $86 \%$ of those making between $\$ 50,000$ - 74,999 and $95 \%$ of those making more than $\$ 75,000 "$ (Lamb, 2013, 7).

- Age: Being 65 or older is a strong predictor of lack of Internet use. 5

One might assume that as technology advances in its sophistication, it will also alleviate the social inequalities associated with it. Perhaps surprisingly, however, there is good reason to think that in some respects things are getting worse. In particular, broadband communication technology is broadening the digital divide. Consider that in June 2000, $34 \%$ of American adults accessed the Internet at home via dial-up versus 3\% who accessed the Internet at home via broadband. A decade later, in May 2010, more than $66 \%$ of American adults accessed the Internet at home via broadband and only $5 \%$ via dial up (Lamb, 2013, 10). Lamb explains the significance of this technological shift in terms of access:

The slower dial-up Internet connections that dominated the Internet landscape in its early days were widely available due to the ubiquity of telephone and electrical service, the two utility components needed for dial up access. The high penetration rate of telephone technology, at over 94\%, made adoption of dial up Internet as simple as buying a computer, buying a modem and signing up for service. However, broadband Internet, which is a much faster and more reliable upgrade over dial-up service, required Internet service providers to build out networks with higher bandwidth capacities than the existing telephone networks. Broad access suffered because Internet service providers rolled out these new more expensive services in higher income areas and charged accordingly. This initial deployment of broadband Internet services left the poor shut out because they could scarcely pay for access to dial up service, let alone the higher prices for new broadband service (Lamb, 2013, 9).

The shift toward broadband technology has created a "soft" digital divide; the divide between those accessing the Internet via broadband, and those whose access utilizes inferior technology, such as dial-up (the latter are predominantly poor and rural users). This "soft" divide is still an important divide in access and not only quality of use, because with the prevalence of broadband technology, much of the content on the Internet (YouTube videos are but one example) simply cannot be seen with a dial-up connection (Lamb, 2013, 10-11).

Indeed, the inequalities in access to Internet services are an important consideration when assessing the degree to which the Internet is "democratizing" the public sphere. ${ }^{6}$ However, access by itself is not the only factor to consider, and arguably not 
even the most important. Hargittai has studied patterns of Internet usage extensively. Her research shows that the skills one needs in order to use the Internet effectively are to a large extent more stratified than the access itself (Hindman, 2009, 9).

Some might suggest that skill stratification will correlate more with age than other variables, since many consider youth to be "digital natives." Hence, according to this logic, the "skill divide" is not a democratic deficit, but rather a natural process of cultural adaptation to new technologies. ${ }^{7}$ To examine this "generational" argument regarding the skill divide, Hargittai examined the variation in Internet skills among youth - the "Net Generation." She studied how people differ in their online abilities and activities, especially in younger populations (Hargittai, 2010, 92). Her findings are informative.

First, Hargittai finds that increased Internet access does not necessarily translate to increased Internet skills (Hargittai, 2010, 93). This means we should be concerned about disparities in Internet skills above and beyond our concern for access. Second, her findings with respect to Internet usage skills do point to reasons for concern regarding social stratification. Her research finds that among younger populations, socio-economic status and education (including the educational level of parents) are positively correlated to higher levels of Internet skill (Hargittai, 2010, 106-108). When examined through the lens of race, the findings show that youth of Asian and White ethnicities present better Internet skills than those of Black and Hispanic youth (Hargittai, 2010, 105).

Perhaps the most important finding related to Internet usage skills and social stratification is the ways in which these skills are put to use. To assess this, Hargittai examined what she calls "Internet usage diversity." That is, the diversity of Web sites accessed by individuals on average. Perhaps unsurprisingly, the overwhelmingly determining variable for diversity in Internet usage was level of skill (Hargittai, 2010, 109). More interesting than the simple category of site diversity is the kind of sites accessed by youth. For the purposes of her study, Hargittai distinguishes between two kinds of activities over the Internet: (1) capital enhancing activities and (2) recreational activities. Capital enhancing activities are defined as activities aimed at advancing one's social and financial capital, positively affecting one's socio-economic status. Examples of capital enhancing activities might be seeking health information, engaging in financial transactions, job search, reading the news, and so on. Recreational activities are defined as activities aimed at pleasure. These may include playing games, gambling, casual browsing, and so on. Perhaps the most important finding is that higher levels of education and higher level of Internet usage skill are positively correlated with more capital enhancing activities (Hargittai, 2010, 95). This suggests that rather than leveling the playing field, Internet usage is reinforcing the socially stratified status quo.

So far we have examined the Internet as a whole. But some might argue that while online trends raise concerns, social networking sites (SNS) in particular deserve special attention. Since SNS such as Facebook, Twitter, YouTube, and others, are often lauded as catalysts for increased access to political participation, it is worth examining whether the stratifying trends that apply to the Internet also affect SNS and if so, whether they affect them differently.. If similar trends do not apply to SNS, then it may be possible to view such sites as "democratizing," even if the broader usage of the Internet is not.

Unfortunately, here too Hargittai shows that "use of such sites is not randomly distributed across a group of highly wired users. A person's gender, race and ethnicity, and parental educational background are all associated with use [of social networking sites]" 
(Hargittai, 2007). ${ }^{8}$ When using measures of the intensity (time spent on sites) and diversity (how many social networking sites are utilized) of SNS usage, studies show that the use of SNS is not random, and is directly motivated by social circumstances (Hargittai and Hsieh, 2010, 516-518).

Finally, in order to assess the possibility that Internet-based platforms will increase participation in democratic processes, some studies compared trends of participation in such processes (for example, in town hall meetings regarding municipal issues) when participants were given the options of participating in person or via the Internet. Findings show that socially advantaged groups tended to participate more in general, and in particular tended to participate more in person. For example:

- Men (especially educated, politically concerned, male Caucasians) participated more in all forms of participation, but dominated in live participation, while women participated in greater percentages online (Monnoyer-Smith, 2012, 196, 201). ${ }^{9}$

- Homeowners participated more than tenants in general, and tenants participated more online than live (Monnoyer-Smith, 2012, 197).

- $\quad$ The educated dominated all participation forms, and the uneducated were much more likely to participate online than live (Monnoyer-Smith, 2012, 198).

Some scholars view such findings as endorsing a more optimistic hypothesis, namely, that Internet platforms do in fact offer disadvantaged groups a medium for democratic participation in which they feel more comfortable. This hypothesis rests on the assumption that citizens choose to participate online or offline "because they feel the technological arrangement provided is the best suited to their ability to express themselves, considering the distribution of power within the deliberative space" (Monnoyer-Smith, 2012, 193).

However, this optimism may be misplaced. We need not assume that individuals made the choice about online or offline participation based on what was perceived by them to be in their best interest. It may be that their choices were constrained by available time, other commitments, and so on. For example, attending a town hall meeting in person requires more time (to get to and from the meeting). It also requires more control over one's time, which is often a luxury of socially advantaged individuals.

What is more, researchers have found that in circumstances where online and offline modes of participation were available, in-person deliberation tended to support "acquisition and exchange of information" while online participants focused more on the accumulation of information (Monnoyer-Smith, 2012, 202-203). That is to say, not all forms of democratic participation are created equal. In many cases where individuals of disadvantaged social groups feel less comfortable with face-to-face deliberation, and might nevertheless be able to participate online, these individuals are more likely to be losing out on the opportunity to have their voices heard.

\section{The Infrastructure Divide}

For the most part, we experience the Internet visually through what appears on our screen. This is the Internet's "front end," or user interface. Hence, less attention is given to what happens behind the scenes in the Internet's "back end." When considering this "back end," we may think of various kinds of infrastructures that make our user experience possible. This includes hardware such as computers, cables, satellites, giant servers that 
store and process information, and more. The infrastructure also includes software, codes, algorithms and so on.

Hence, the structure of the Internet is often described in terms of three layers: (1) the hardware layer; (2) the code layer; and (3) the content layer. Matthew Hindman has suggested that the link structure of the Internet is underrepresented in this tripartite schema, and that this link structure is central in determining the flow of information on the Internet. In order to capture the significance of this additional component, Hindman suggests distinguishing a fourth layer - search (Hindman, 2009, 39-40). In fact, search engines span through all three layers of hardware, code and content. The algorithm that technology companies design for their search engines are key to understanding Internet use patterns. Hindman explains that "[t]he network protocols that route data packets around the Internet and the HTML code used to create Web pages say nothing about search engines, and yet these tools now guide (and powerfully limit) most users' online search behavior. The technological specifications allow hyperlinks to point anywhere on the Web, yet in practice social processes have distributed them in winners-take-all patterns" (Hindman, 2009, 15).

It is true that the Web provides users with millions of choices about where to go to get information, news, and so on. But the fact that these options are available in principle, does mean that users utilize these options in practice. In fact, patterns of Internet usage make it clear that they do not (Hindman, 2009, 56). The reason for "winner-takes-all" patterns in Internet usage and visits to sites is not primarily direct commercial pressure. Rather, the reason lies in the design of the Internet: "online concentration comes from the sheer size of the medium and the inability of any citizen, no matter how sophisticated and civic-minded, to cover it all" (Hindman, 2009, 57). Hence, the function of search algorithms is to narrow down the choices, and highly networked sites - based on the link structure almost always prevail.10

When discussing the "infrastructure divide," it is important to focus on the physical infrastructure of search engines as well. Google Search, for example, is backed by vast physical servers that store Web content. It is because of these vast servers, which cost billions of dollars annually to purchase and maintain, that Google is able to provide the search and date storage capacity that it does. A 2009 study showed that Google spent as much on physical equipment as a typical telephone company (Hindman, 2009, 85). This suggests that the Internet may not be lowering socio-economic barriers to entry, but rather rearranging the location of the barriers.

In the case of traditional newspapers, for example, it is often pointed out that the infrastructure needed to enter the market poses a barrier to newcomers. Hence, it is not surprising that for the past several decades, less than 1\% of U.S. daily newspapers have had a direct competitor in the same city (Hindman, 2009, 83). On the face of things, the case of the Internet is different. One does not need to overcome the costs of printing and distribution. But this misguided analysis ignores the structure of how information is found and circulated online. Creating content is relatively easy. Attracting online traffic to that content at scale is far from easy, and the search and link structures work against newcomers. ${ }^{11}$

\section{Social Critique Informing Technological Design}


The critical picture we have painted need not leave us powerless in the face of the concerns raised regarding the role of digital communications in promoting a deliberative democracy. The design of the technologies under discussion, and hence their social consequences, are not predetermined. As critical theorists of technology have convincingly argued, society simultaneously shapes technology as technology shapes society. Technology is not essentially neutral, but neither is its nature predetermined. Technology is always underdetermined and always embodies specific values. The World Wide Web is no different. As the most prevalent application used over the Internet, the World Wide Web is designed according to certain protocols, and it allows certain actions and functions, but not others. What is important to see is that these design choices have consequences. They determine how, and hence who, will be seen and heard online.

When one considers the underlying infrastructure and political economy of the Internet - the vast server farms, the particular designs of the algorithms, the network's link structure, and so on - the optimistic picture of an Internet that is free and open to all changes, and we get a complex landscape, in which some have more opportunity than others. It seems that some (overly-optimistic) observers of the Internet do not pay enough attention to its underlying industry. It is perhaps fitting, then, to return to Adorno's reflection, in which he explains why, along with Horkheimer, he distinguished between "mass culture" and the "culture industry":

The term culture industry was perhaps used for the first time in the book Dialectic of Enlightenment, which Horkheimer and I published in Amsterdam in 1947. In our drafts we spoke of 'mass culture'. We replaced that expression with 'culture industry' in order to exclude from the outset the interpretation agreeable to its advocates: that it is a matter of something like a culture that arises spontaneously from the masses themselves, the contemporary form of popular art. From the latter the culture industry must be distinguished in the extreme. The culture industry fuses the old and familiar into a new quality. In all its branches, products which are tailored for consumption by masses, and which to a great extent determine the nature of that consumption, are manufactured more or less according to plan (Adorno, 1991, 98).

Our focus here is not on culture per se, but on digital information and democratic participation online. Consider a revised version of Adorno's last sentence in the passage above, as follows:

The Internet information industry fuses the old and familiar into a new quality. In all its branches, products which are tailored for consumption by masses, and which to a great extent determine the nature of that consumption, are manufactured more or less according to plan.

The "plan" here need not be a malicious conspiracy. Rather, the point is that the distribution of access to online participation in processes of democratic opinion and will formation is a result of design. Moreover, there is reason to think that communication technologies can be designed to ameliorate empathy gaps, and position discussants to better experience and understand each other. This means that the design of the Internet 
itself, and the applications we use through it, begs a public discussion based on democratic values.

\section{WORKS CITED}

Adorno, Theodor W. "The Culture Industry Reconsidered." In The Culture Industry: Selected Essays on Mass Culture. London: Routledge, 1991.

Bar-Tura, Asaf. "Arendt, Habermas and Facebook: Participation and Discourse in Cyber Public Spheres," Humanities and Technology Review, Vol. 29 (Fall 2010), pp. 1-25.

Coleman, Stephen and Vincent Price. "Democracy, Distance, and Reach: The New Media Landscape." Connecting Democracy: Online Consultation and the Flow of Political Communication. Edited by Stephen Coleman and Peter M. Shane. Cambridge: MIT, 2012. 23-43.

Dean, Jodi. Democracy and other Neoliberal Fantasies: Communicative Capitalism and Left Politics. Durham: Duke University Press, 2009.

Donaldson, Stewart I., and Elisa J. Grant-Vallone. "Understanding Self- Report Bias in Organizational Behavioral Research." Journal of Business and Psychology 17.2 (2002): 245-60.

Druckman, James. "Political Preference Formation: Competition, Deliberation and the (Ir)relevance of Framing Effects.” American Political Science Review 98 (2004): 67186.

Fishkin, James. "Experimenting with a Democratic Ideal: Deliberative Polling and Public Opinion." Acta Politica 40 (Sept. 2005), pp. 284-98.

Grossman, Lev. “Time's Person of the Year: You.” Time Magazine. December 13, 2006. Retrieved from http://www.time.com/time/magazine/article/0,9171,1569514,00.html (December 14, 2010).

Habermas, Jürgen. Between Facts and Norms: Contributions to a Discourse Theory of Law and Democracy. Cambridge, MA: MIT Press, 1998.

Habermas, Jürgen. Europe: The Faltering Project. Malden, MA: Polity Press, 2009.

Habermas, Jürgen. The Structural Transformation of the Public Sphere: An Inquiry into a Category of Bourgeois Society. Cambridge, MA: MIT Press, 1989. 
Hargittai, Eszter. "Whose Space? Differences Among Users and Non-Users of Social Network Sites." Journal of Computer-Mediated Communication, Vol. 13, No. 1 (October 2007), 276-297.

Hargittai, Eszter. "Digital $\mathrm{Na}(\mathrm{t})$ ives? Variation in Internet Skills and Users among Members of the 'Net Generation'." Sociological Inquiry, Vol. 80, No. 1 (February 2010), 92-113.

Hargittai, Eszter, and Yu-li P. Hsieh. "Predictors and Consequences of Differentiated Practices on Social Network Sites." Information, Communication \& Society, Vol. 13, No. 4 (2010), 515-536.

Hindman, Matthew. The Myth of Digital Democracy. Princeton: Princeton University Press, 2009.

Kellner, Douglas. "Habermas, the Public Sphere and Democracy: A Critical Intervention.” In Perspectives on Habermas. Edited by Lewis Edwin Hahn. Chicago: Open Court, 2000.

Lamb, Jason M. "The Digital Divide: Free Expression, Technology and a Fair Democracy” (March 20, 2013). Available at SSRN: http://ssrn.com/abstract=2245072 or http://dx.doi.org/10.2139/ssrn.2245072

Monnoyer-Smith, Laurence. "The Technological Dimension of Deliberation: A Comparison between Online and Offline Participation." Connecting Democracy: Online Consultation and the Flow of Political Communication. Edited by Stephen Coleman and Peter M. Shane. Cambridge: MIT, 2012.

Neblo, Michael. "Change for the Better? Linking the Mechanisms of Deliberative Opinion Change to Normative Theory. In M. Neblo, Common Voices: The Problems and Promise of a Deliberative Democracy (forthcoming). Available online at http://polisci.osu.edu/faculty/mneblo/papers/ChangeC4.pdf.

Schmitt, Carl. The Crisis of Parliamentary Democracy. Cambridge, MA. MIT Press, 1985.

\footnotetext{
${ }^{1}$ Habermas cites experiments involving full informed deliberation - from the collective decision discussions of Michael Neblo (2008) to the fully informed focus-group polling of James Fishkin (2005).

${ }^{2}$ See his discussion of how interpretative frames and social perspectives shape preferences, and how face-to-face conversations involving "heterogeneous groups" can counter parochialism (Habermas, 2009, 151; Druckman, 2004).

${ }^{3}$ See cover image at: http://www.time.com/time/covers/0,16641,20061225,00.html (last retrieved December 14, 2010).

${ }^{4}$ It may be helpful to clarify the difference between the "Internet" and the "World Wide Web," since these are often, mistakenly, used interchangeably. The Internet is the name for the large-scale interconnection of computer networks. The World Wide Web ("the Web") is one (the most popular) software application used on this interconnected network. The Web uses an Internet language ("protocol") called Hypertext Transfer Protocol (or
} 
HTTP). Most content on the Internet appears on Web "pages" that use the HTTP protocol (hence Web pages have the http:// prefix before the page address).

${ }^{5}$ This should not be read as suggesting that young people are all indeed "digital natives." As of $2008,25 \%$ of young people in the US do not have Internet access. Furthermore, lack of access presents a strong positive correlation with lower socioeconomic status (Hargittai, 2010, 94).

${ }^{6}$ We follow Hindman in using the verb "democratizing" here descriptively. That is, for the Internet to be democratizing means it is "redistributing political influence; it is broadening the public sphere, increasing political participation, involving citizens in political activities that were previously closed to them, and challenging the monopoly of traditional elites" (Hindman, 2009, 6). Hindman adds that "proponents of participatory citizenship, deliberative citizenship, and monitorial citizenship all focus on political equality - and particularly on making formal political equality meaningful in practice" (Hindman, 2009, 8).

${ }^{7}$ Research does in fact show that youth embrace new media technologies faster than older populations (see: Coleman and Price, 2012, 36). However, one should proceed with caution: research shows that while general Internet use over-represents younger populations, online politics does not (see Hindman, 2009, 68).

${ }^{8}$ In particular, the level of parental education is shown to correlate very strongly with specific ways of SNS interaction. For example, individuals with college-level (and above) educated parents are much more likely to engage in "strong-tie" activities (i.e. activities involving close friends) via SNS (Hargittai and Hsieh, 2010, 526527). Furthermore, savvy Internet skills positively correlate to student GPA (Hargittai and Hsieh, 2010, 525, 531). ${ }^{9}$ The gender variable is interesting in many ways. For example, when asked to self-report Internet proficiency, women tend to claim lower levels of proficiency regarding Internet-related terms than men. However, other research that was able to measure both actual and perceived online Internet abilities found that women rate their Internet proficiency lower than their actual observed skills. (Hargittai, 2010, 104-106). For more on bias in self-reporting see Donaldson and Grant-Vallone, 2002.

${ }^{10}$ Jodi Dean has an insightful discussion of how network structures work, and consequently of the ways in which the technology behind the Internet does not provide equal opportunity for varying sites to be seen, and the voices presented by them to be heard. She explains that as in any network (cyber or "real"), "[h]ierarchies and hubs emerge out of growth and preferential attachment." Smaller, newer, or lesser known sites that seek publicity and attention on the Web, will attach themselves through various links to sites that have established themselves as central hubs. In the process, clusters of networked power inevitably form (Dean, 2009, 27-30).

${ }^{11}$ A note of caution is in order here: From the description of infrastructure divide above, one might conclude that if there was a diverse competitive market in various domains of the Internet (for example, Google, Yahoo and to a lesser extent Microsoft have dominated the Internet search market for years), then we would have more diversity in which sites get seen and read. But this is not necessarily the case. Studies have found that Yahoo and Google searches, for example, still produce much of the same search results in the first results pages. This is especially significant since past studies have shown that users rarely click on a search result beyond the first page. One study found that $90 \%$ of users clicked on a link presented in the first page of results (Hindman, 2009, 59-60, 69). 